\title{
PERKEMBANGAN HUTAN KEMASYARAKATAN DI PROVINSI LAMPUNG (Progress of Community Forest in Lampung Province)
}

\author{
Sanudin $^{1 *}$, San Afri Awang ${ }^{2}$, Ronggo Sadono² dan Ris Hadi Purwanto \\ ${ }^{1}$ Program Doktor Ilmu Kehutanan, Fakultas Kehutanan, Universitas Gadjah Mada, \\ Jl. Agro No.1 Bulaksumur, Yogyakarta 55281. \\ ${ }^{2}$ Fakultas Kehutanan, Universitas Gadjah Mada, Jl. Agro no.1 Bulaksumur, Yogyakarta 55281.
}

*Penulis korespondensi. Tel: 0265-771352. Email : sanevafa2014@gmail.com.

Diterima: 1 Februari 2016

Disetujui: 29 Juni 2016

\begin{abstract}
Abstrak
Hutan Kemasyarakatan (HKm) di Provinsi Lampung sudah berjalan sejak 14 tahun yang lalu dengan segala dinamika dalam implementasinya. Penelitian terhadap perkembangan $\mathrm{HKm}$ sangat dibutuhkan. Penelitian ini bertujuan untuk mengetahui perkembangan HKm di Provinsi Lampung yang dibatasi pada sebaran, permasalahan dan kondisi yang diharapkan. Penelitian dilakukan pada bulan September-Desember 2014. Data dikumpulkan melalui wawancara terbuka dan semi struktur menggunakan kuesioner dan pengamatan langsung. Informasi penyebaran $\mathrm{HKm}$ diperoleh melalui kegiatan survai dan identifikasi terhadap semua kabupaten yang ada di Provinsi Lampung. Permasalahan yang dihadapi dalam implementasi $\mathrm{HKm}$ dan kondisi yang diharapkan dikumpulkan melalui wawancara dengan kelompok tani dan pertemuan/sosialisasi tentang HKm yang dilakukan oleh Dinas Kehutanan Kabupaten/Provinsi. Data yang terkumpul kemudian dianalisis menggunakan diagram tulang ikan (Fishbone Diagram) dan diuraikan secara deskriprif. Hasil penelitian menunjukkan bahwa HKm di Provinsi Lampung merupakan solusi terhadap permasalahan konflik pengelolaan hutan dengan tingginya tingkat ketergantungan masyarakat terhadap hutan yang telah mendorong kegiatan penggarapan kawasan hutan. HKm di Provinsi Lampung tersebar di 9 kabupaten dari 15 kabupaten/kota yang ada baik yang sudah mendapatkan Izin Usaha Pemanfaatan HKm (IUPHKm), mendapatkan Penetapan Areal Kerja (PAK), maupun sedang mengusulkan PAK. Permasalahan utama dalam implementasi HKm adalah dukungan anggaran yang kurang memadai akibat HKm belum menjadi program prioritas sehingga pembinaan dan pendampingan yang dilakukan kurang maksimal. Pengembangan kelembagaan kelompok tani, lahan, dan kewirausahaan merupakan tiga kunci penting untuk mencapai tujuan $\mathrm{HKm}$ yakni untuk meningkatkan kesejahteraan masyarakat dan menjaga kelestarian hutan.
\end{abstract}

Kata kunci: hutan kemasyarakatan, kondisi yang diharapkan, konflik, pengelolaan, permasalahan, sebaran.

\begin{abstract}
Community Forest (HKm) in Lampung Province has to be 14 years of age with its dynamics on implementation. Studies on HKm progres is needed. The study aimed is to know progress of HKm especially distribution, problem and expectation condition. The study was conducted in September to December 2014 in Lampung Province. Data was collected using open ended and semi-structured questionnaire interview and direct observation. Information of HKm distribution obtained through survey and identification of districts in Lampung Province. Problem faced and expectation condition on implementation of HKm were collected through interview with farmer groups and national, provincial or district forestry offices and meeting/socialization about HKm. Data was analyzed using a fishbone diagram and descriptive. The results showed that HKm is a solution on problem of forest management conflict, community around the forest have very high dependence upon the forest, its caused forest conversion in Lampung Province. HKm (licence issues for community forest/IUPHKm, determination of community forest working area/PAK) in Lampung Province distributed on 9 of 15 districts. The main problems on HKm implementation was limited of budget support.. HKm is not a priority program so coaching and mentoring are not maximum. Development of farmer groups, land, and entrepreneurship are keys for increase of local welfare and to maintain the wholeness of forest and their functions.
\end{abstract}

Keywords: community forest, expected condition, conflict, management, problem, distribution.

\section{PENDAHULUAN}

Di Indonesia, sejak awal era reformasi dan kebijakan desentralisasi pada tahun 1998, pengelolaan hutan telah bergeser secara bertahap dari state based forest management menjadi community based forest management (Barr dkk.,
2001; Obidzinski dan Barr, 2003). Kebijakan community based forest management ini menjadi bagian dari koreksi terhadap pengelolaan hutan yang didominasi oleh usaha skala besar dalam kebijakan pada masa lalu yang telah mengakibatkan ketimpangan akses, menimbulkan dampak kemiskinan masyarakat yang hidupnya tergantung 
pada hutan, dan memicu konflik antara pemegang izin/konsesi dan masyarakat setempat (Suhirman dkk., 2012). Banyak pihak memandang kebijakan ini sebagai pengakuan negara terhadap pengelolaan hutan oleh rakyat yang selama ini terabaikan, namun mampu menjaga kelestarian alam dan memberikan kesejahteraan bagi masyarakat. Kehutanan masyarakat merupakan penghubung terhadap upaya pengentasan kemiskinan, pemberdayaan masyarakat sekitar hutan dan peningkatan kondisi hutan (Maryudi dkk., 2012).

Perubahan paradigma pengelolaan hutan dari state based menjadi community based tersebut memberi implikasi yang luas terutama terhadap kesiapan dan penguatan masyarakat untuk memperoleh hak dan akses dalam pengelolaan sumberdaya hutan baik secara individu maupun kelompok (Awang dkk., 2000). Meskipun Departemen Kehutanan terus melakukan kontrol secara keseluruhan terhadap sebagian besar kawasan hutan di Indonesia, beberapa kemajuan telah dibuat dalam rangka membuka ruang untuk negosiasi antara masyarakat dan pemerintah (Fay dkk., 2000).

Peraturan Pemerintah No 6 tahun 2007 tentang Tata Hutan dan Penyusunan Rencana Pengelolaan Hutan serta Pemanfaatan Hutan menyebutkan bahwa untuk mendapatkan manfaat sumber daya hutan secara optimal dan adil, dilakukan pemberdayaan masyarakat setempat, melalui pengembangan kapasitas dan pemberian akses dalam rangka peningkatan kesejahteraannya. Salah satu bentuk pemberdayaan masyarakat setempat dapat dilakukan salah satunya melalui Hutan Kemasyarakatan $(\mathrm{HKm})$. Penyelenggaraan $\mathrm{HKm}$ dimaksudkan untuk memberikan akses (Arifin, 2006; Arifin dkk., 2009) dan mengembangkan kapasitas masyarakat sekitar hutan dalam mengelola hutan secara lestari guna menjamin ketersediaan lapangan kerja untuk memecahkan persoalan ekonomi dan sosial yang terjadi di masyarakat (Dwiprabowo dkk., 2013).

HKm di Provinsi Lampung sudah berlangsung hampir 14 tahun dengan segala dinamika dalam implementasinya. Oleh karena itu penelitian terhadap perkembangan $\mathrm{HKm}$ sangat diperlukan. Penelitian ini bertujuan untuk mengetahui perkembangan $\mathrm{HKm}$ di Provinsi Lampung yang dibatasi pada sebaran, permasalahan dan kondisi yang diharapkan.

\section{METODE PENELITIAN}

\section{Waktu dan Lokasi}

Penelitian dilakukan pada bulan September Desember 2014 di Provinsi Lampung. Lampung dipilih sebagai lokasi penelitian dengan pertimbangan bahwa Lampung merupakan provinsi yang sarat dengan konflik pengelolaan kawasan hutan.

\section{Pengumpulan dan Analisis Data}

Data dikumpulkan melalui wawancara terbuka dan semi struktur menggunakan kuesioner dan pengamatan langsung. Informasi penyebaran $\mathrm{HKm}$ diperoleh melalui survai dan identifikasi terhadap semua kabupaten yang ada. Permasalahan yang dihadapi dalam pengelolaan HKm serta kondisi yang diharapkan dikumpulkan melalui wawancara dengan kelompok tani dan pertemuan/sosialisasi HKm yang dilakukan oleh dinas kehutanan kabupaten/provinsi.

Kelompok tani yang menjadi contoh tersebar di tiga kabupaten sebagai representasi dengan mempertimbangkan tingkat perkembangan $\mathrm{HKm}$ yakni Desa Karang Jaya Lampung Selatan (kelompok tani yang sedang mengajukan Penetapan Areal Kerja/PAK ke Menteri Kehutanan), Desa Beringin Jaya dan Desa Abang Ulu Kabupaten Tanggamus (kelompok tani yang sudah mendapatkan PAK), serta Desa Tugu Sari dan Desa Tribudi Sukur Kabupaten Lampung Barat (kelompok tani yang sudah mendapatkan izin $\mathrm{HKm}$ ). Data yang terkumpul dianalisis menggunakan diagram tulang ikan (fishbone diagram) dan diuraikan secara deskriprif. Menurut Scarvada dkk. (2004), diagram tulang ikan umumnya digunakan untuk mengidentifikasi permasalahan dan menentukan penyebab dari permasalahan tersebut.

\section{HASIL DAN PEMBAHASAN}

\section{Kondisi Hutan}

Berdasarkan SK Menteri Kehutanan dan Perkebunan No 256/Kpts-II/2000 tanggal 23 Agustus 2000, luas hutan di Provinsi Lampung seluas 1.004 .735 ha atau $30,43 \%$ dari total luas daratan Provinsi Lampung yang terdiri dari hutan konservasi 462.030 ha $(13,99 \%)$, hutan lindung 317.615 ha $(9,62 \%)$, hutan produksi 33.358 ha (1.01\%), dan hutan produksi tetap seluas 191.732 ha $(5,81 \%)$. Hasil wawancara dengan Pejabat di Dinas Kehutanan Provinsi dan kabupaten contoh (Lampung Selatan, Tanggamus, dan Lampung Barat) serta hasil pengamatan lapangan di beberapa kawasan hutan lindung seperti Register 17 (Batu Serampok, Lampung Selatan), Register 30-32 (Gunung Tanggamus, Tanggamus), dan Register 45 B (Bukit Rigis, Lampung Barat) diketahui bahwa sebagian besar kawasan hutan di Provinsi Lampung telah dirambah dan secara perlahan-lahan pemanfaatannya berubah menjadi lahan budidaya baik tanaman semusim maupun perkebunan (kopi, coklat). Lampung merupakan salah satu provinsi di Indonesia yang secara fisik kawasan hutannya mengalami kerusakan paling parah, setidaknya 
$56,45 \%$ kawasan hutan telah mengalami kerusakan (Anonim, 2012 ${ }^{\mathrm{a}}$ ).

Sejak tahun 1977/1978, jumlah penduduk Provinsi Lampung meningkat dengan pesat. Hal ini menjadi alasan utama pemerintah menghentikan program transmigrasim meskipun perpindahan penduduk dari Pulau Jawa ke Provinsi Lampung masih berlangsung sampai saat ini (Safitri, 2006). Jumlah penduduk Provinsi Lampung per Juni 2014 sebanyak 8.026 .000 orang $(3,18 \%$ dari jumlah penduduk Indonesia), kepadatan penduduk 232 jiwa $/ \mathrm{km}^{2}$ (Indonesia, $132 \mathrm{jiwa} / \mathrm{km}^{2}$ ) dengan laju pertumbuhan 1,26\% (Indonesia, 1,4\%) (Anonim, $2014^{a}$ ). Peningkatan jumlah penduduk ditambah dengan keterbatasan lahan yang tersedia sehingga menyebabkan penggarapan lahan di kawasan hutan (Verbist dan Pasya, 2004).

Sebagian bagian dari upaya peningkatan ekspor, pemerintah pusat berusaha mendorong ekspor salah satunya melalui perluasan wilayah penanaman kopi yang kemudian menyebabkan terjadinya perubahan fungsi kawasan hutan (Verbist dkk., 2005). Masih menurut Verbist dkk. (2005), akibat perubahan fungsi kawasan hutan menjadi perkebunan kopi dalam tiga dekade terakhir, penutupan hutan di Sumberjaya, Lampung Barat mengalami penurunan hingga mencapai 50\%.

Deforestasi yang marak terjadi di Provinsi Lampung yang diikuti dengan konversi lahan menjadi sistem tanam kopi terbuka (clean weeded) secara monokultur merupakan penyebab utama penurunan ketersediaan air di hilir sungai dan hilangnya fungsi perlindungan Daerah Aliran Sungai (Verbist dkk., 2004). Fenomena alih fungsi hutan (hutan lindung, hutan produksi terbatas, taman nasional) menjadi kebun-kebun kopi yang dilakukan dengan pola ekstensifikasi bukan hal yang baru di Lampung melainkan sejak zaman kolonial misalnya Kabupaten Lampung Barat. Lampung Barat merupakan daerah yang direncanakan Belanda sebagai daerah sentra kopi (Anonim, 2007).

Pada awal tahun 1980-an, Pemerintah Indonesia meluncurkan program reboisasi dan mengganti kopi dengan jenis pohon seperti mahoni (Swietenia sp.) dan kaliandra (Calliandra calothyrsus) untuk mengembalikan fungsi kawasan hutan serta memindahkan masyarakat yang bermukim di dalam kawasan hutan ke luar kawasan hutan (Suyanto dkk., 2005; Verbist dkk., 2005). Program tersebut menyebabkan masyarakat kehilangan mata pencaharian dan menimbulkan kerawananan sosial.

\section{Perkembangan Hutan Kemasyarakatan (HKm)}

Saat ini terdapat \pm 380 desa di Provinsi Lampung yang berada di sekitar kawasan hutan dan $\pm 1,33$ juta jiwa tinggal di dalam dan sekitar kawasan hutan. Kondisi ini mendorong kondisi sosial yang kurang kondusif terhadap pelestarian hutan dan masalah tenurial sehingga program Hutan Kemasyarakatan $(\mathrm{HKm})$ diharapkan memberikan jalan tengah bagi tercapainya tujuan pengelolaan hutan yakni hutan lestari dan masyarakat sejahtera.

Praktek pengelolaan hutan dengan melibatkan masyarakat di Provinsi Lampung telah berjalan sejak lama yang dimulai dengan adanya pola berkebun 'repong damar' yang dilakukan masyarakat Krui di Lampung Barat. Pemerintah kemudian memberikan pengakuan terhadap pengelolaan hutan tersebut dengan keluarnya SK Menhut No 47/Kpts-II/1995 yang menetapkan kawasan hutan Krui seluas 29.000 ha sebagai kawasan dengan tujuan istimewa (Anonim, 2012 ${ }^{\mathrm{a}}$ ).

Titik awal HKm di Lampung dimulai pada tahun 1998 dengan terbitnya SK Menhutbun No 677/Kpts-II/1999 tentang HKm dan Izin Usaha Pemanfaatan HKm (IUPHKm) pertama diberikan oleh Menteri Kehutanan kepada Kelompok Pengelola dan Pelestari Hutan (KPPH) Sumber Agung di Register 19 Gunung Betung Tahura Wan Abdul Rahman. Pada saat peluncuran Permenhut No P.37/Kpts-II/2007 tentang $\mathrm{HKm}$ pada bulan Desember 2007 di Yogyakarta, Provinsi Lampung mendapat target $\mathrm{HKm}$ seluas 85.280,21 ha pada 2009 dari target 400.000 ha pada tingkat nasional (Pahlawanti dan Saroso, 2009).

Meskipun Provinsi Lampung cukup awal mengembangkan program $\mathrm{HKm}$, namun dalam pelaksanaannya di kabupaten/kota berbeda-beda, ada yang sudah mengimplementasikan di lapangan, sedang menyusun proposal, maupun baru dalam tahap pencermatan (Widyastuti, 2013). Sebagian besar HKm di Provinsi Lampung tersebut baik yang berizin definitif (IUPHKm) maupun yang sedang dalam proses pengajuan berada di kawasan hutan lindung.

Data sampai tanggal 30 September 2014 menyebutkan bahwa Provinsi Lampung mempunyai Penetapan Areal Kerja (PAK) dari Menteri Kehutanan terbanyak dibandingkan dengan provinsi lain (34\%) dan IUPHKm yang telah diterbitkan tersebar di 9 kabupaten dari 15 kabupaten/kota yang ada di Provinsi Lampung (Anonim, 2014 ${ }^{\mathrm{b}}$ ). Perkembangan HKm di Provinsi Lampung sampai Desember 2013 disajikan pada Tabel 1.

Dari Tabel 1 dapat dilihat bahwa realisasi IUPHKm dan PAK seluas $64.430,74$ ha $(75,80 \%)$ dari total target $\mathrm{HKm}$ seluas 85.000 ha pada tahun 2015 (Anonim, 2012 ${ }^{\mathrm{b}}$ ). Hal ini menunjukkan bahwa perkembangan $\mathrm{HKm}$ di Provinsi Lampung berkembang cukup baik.

Jenis tanaman yang dikembangkan dalam HKm berbeda-beda sesuai dengan kondisi biofisiknya dan sistem penanaman yang dikembangkan adalah multi 
strata tajuk. Sistem multi strata tajuk tersebut memiliki dua fungsi yakni fungsi lindung terhadap tanah dan fungsi finansial dengan memberikan pendapatan bagi petani secara berkelanjutan.

Jenis tanaman yang dikembangkan di Kabupaten Lampung Selatan adalah jenis Multi Purpose Tree Species (MPTs) sebagai tanaman bertajuk tinggi dan coklat sebagai tanaman bertajuk pendek. Jenis MPTs yang dominan dikembangkan seperti durian (Durio zibethinus), petai (Parkia speciosa), jengkol (Archidendron pauciflorum), dan kemiri (Aleurites moluccana).

Kopi yang bagi masyarakat Lampung merupakan tanaman penting baik dari segi ekonomi maupun budaya banyak dikembangkan sebagai tanaman tajuk pendek di Kabupaten Lampung Barat dan Kabupaten Tanggamus, sementara untuk tajuk sedang dan tajuk tinggi dikembangkan MPTs seperti alpukat (Persea americana), nangka (Artocarpus heterophyllus), petai. Selain mempunyai peran dalam aspek ekonomi dan budaya, kopi sebagai tanaman utama yang tumbuh dengan naungan pohon dalam beberapa bentuk agroforestry juga mempunyai peran sebagai penyedia jasa ekosistem seperti konservasi biodiversitas (Philpott dkk., 2008), penyerapan karbon (Albrecht dan Kandji, 2003), dan pencegahan erosi tanah (Beer dkk., 1998).

\section{Permasalahan yang Dihadapi}

Provinsi Lampung mempunyai perkembangan HKm cukup progresif dibandingkan provinsi lain di
Indonesia, namun dalam perjalanannya masih menghadapi beberapa permasalahan di antaranya adalah dukungan anggaran yang kurang memadai dan kapasitas pemerintah yang kurang dalam memfasilitasi pengembangan HKm. Hasil pertemuan Forum HKm Provinsi Lampung pada bulan November 2014 yang melibatkan seluruh stakeholder yang terkait dengan HKm seperti dinas kehutanan provinsi, dinas yang menangani kehutanan seluruh kabupaten/kota, LSM (WATALA, WWF), perwakilan kelompok tani dan hasil studi literatur menunjukkan bahwa banyak permasalahan yang dihadapi dalam implementasi HKm di Provinsi Lampung.

Ringkasan permasalahan dalam implementasi HKm disajikan pada Gambar 1 dalam bentuk diagram tulang ikan (diagram fishbone), sementara usulan perbaikan terhadap permasalahan tersebut disajikan pada Tabel 2.

Gambar 1 dan Tabel 2 menunjukkan bahwa permasalahan utama implementasi HKm di Provinsi Lampung adalah anggaran. Anggaran (APBN maupun APBD) merupakan instrumen penting bagi pemerintah untuk melaksanakan programnya yang dapat dipergunakan sebagai indikator untuk mengukur komitmen dan keberpihakan pemerintah daerah dalam upaya memperbaiki tata kelola hutan dan lahan (Prayitno dkk., 2013). Semua dinas yang mengurusi bidang kehutanan di kabupaten mengeluhkan minimnya anggaran yang dapat digunakan untuk implementasi HKm, termasuk Dinas Kehutanan Provinsi Lampung sendiri.

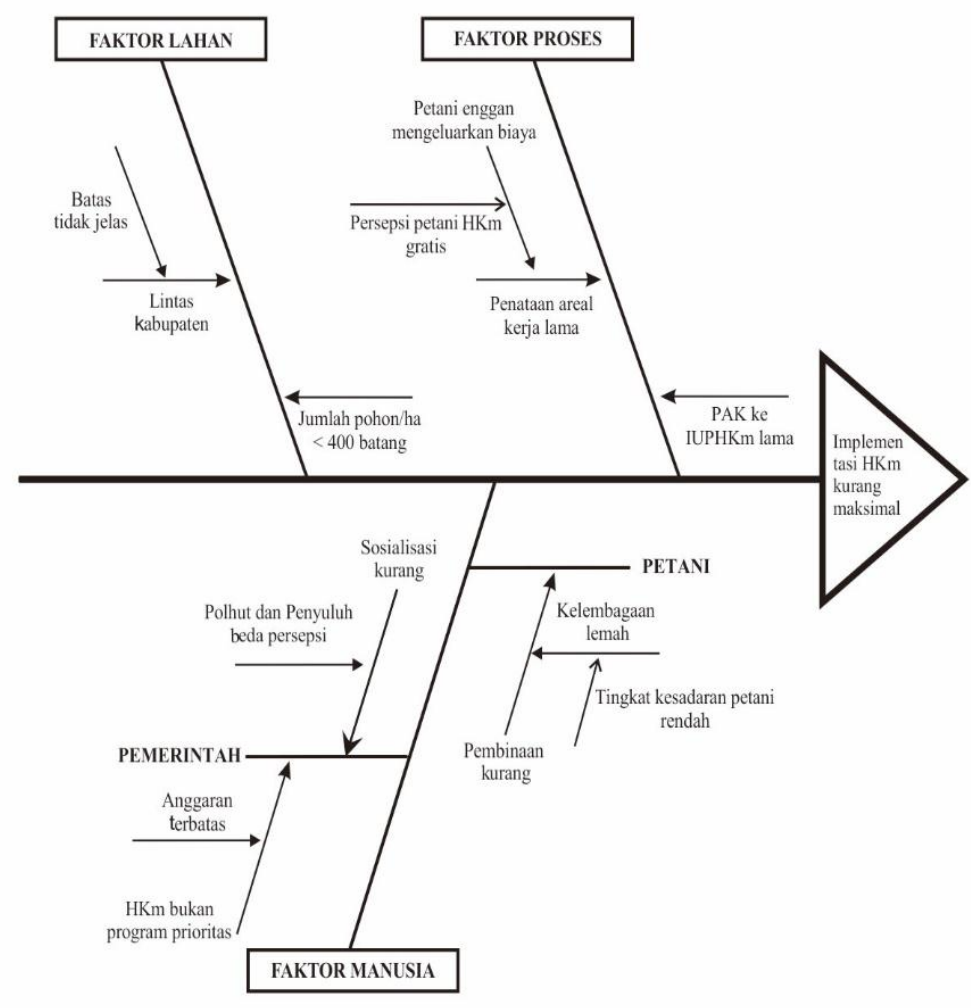

Gambar 1. Diagram Fishbone untuk permasalahan dalam implementasi HKm. 
Tabel 1. Perkembangan HKm di Provinsi Lampung.

\begin{tabular}{|c|c|c|c|c|c|}
\hline No & Kabupaten & $\begin{array}{l}\text { IUPHKm } \\
\text { (ha) }\end{array}$ & $\begin{array}{l}\text { PAK } \\
\text { (ha) }\end{array}$ & $\underset{\text { (ha) }}{\text { Menunggu PAK }}$ & $\begin{array}{c}\text { Usulan ke Bupati } \\
\text { (ha) }\end{array}$ \\
\hline 1. & Lampung Utara & 5.330 & 545 & & 7.500 \\
\hline 2. & Lampung Barat & $6.562,63$ & 8.575 & $16.473,51$ & \\
\hline 3. & Tanggamus & $14.608,52$ & $7.343,86$ & $23.020,18$ & 6.991 \\
\hline 4. & Lampung Tengah & 5.792 & 6.116 & & 705,75 \\
\hline 5. & Way Kanan & 1.295 & 920 & $4.787,58$ & 2.421 \\
\hline 6. & Lampung Timur & & $3.707,51$ & & 3.000 \\
\hline 7. & Lampung Selatan & & & & \\
\hline 8. & Pringsewu & & $3.635,22$ & & 4.320 \\
\hline 9. & Pesawaran & & & & 500 \\
\hline \multicolumn{2}{|c|}{ Jumlah } & $33.588,15$ & $30.842,59$ & $44.281,27$ & $25.437,75$ \\
\hline
\end{tabular}

Sumber: Dinas Kehutanan Provinsi Lampung, 2012, data diolah

Tabel 2. Permasalahan HKm dan usulan perbaikannya di Provinsi Lampung

\begin{tabular}{lll}
\hline No. & Faktor & \multicolumn{1}{c}{ Faktor penyebab } \\
\hline 1. & Manusia & \\
& a. Petani & - Pembinaan yang kurang menyebabkan \\
& & kelembagaan petani lemah sehingga \\
& & tingkat kesadaran petani rendah.
\end{tabular}

b. Pemerintah - Keterbatasan anggaran karena program $\mathrm{HKm}$ belum menjadi prioritas kabupaten.

- Sering terjadi penangkapan terhadap petani HKm karena terjadi perbedaan persepsi antara polisi hutan dan penyuluh akibat sosialisasi yang kurang intensif.

2. Lahan

- Tutupan lahan HKm belum memenuhi ketentuan yang sudah ditetapkan yakni minimal 400 batang pohon/ha.

- Penyelenggaraan Hkm kurang harmonis pada kawasan hutan yang merupakan batas antar kabupaten akibat permasalahan lintas kabupaten yang belum terakomodasi dengan baik, tegas, dan jelas.

3. Proses
- Pemetaan dan pengukuran lahan garapan $\mathrm{HKm}$ oleh petani sering terhambat karena adanya keengganan dari petani untuk mengeluarkan biaya. Hal ini disebabkan adanya persepsi petani bahwa HKm adalah gratis.

- Umumnya proses untuk mendapatkan IUPHKm lebih dari 2 tahun karena menunggu pemetaan dan pengukuran lahan garapan selesai.
- Mendorong pemerintah baik pemerintah daerah kabupaten/provinsi/pusat untuk memfasilitasi HKm dari sisi anggaran.

- Kerjasama dengan LSM melakukan pendampingan kelompok tani.

- Mendorong fasilitasi anggaran dan sumberdaya manusia dari Kementerian Kehutanan.

- Sosialisasi tentang HKm dengan melibatkan pemerintah daerah baik pemerintah kabupaten/provinsi/pusat maupun LSM.

- Sosialisasi hak dan kewajiban kelompok tani dalam pengelolaan $\mathrm{HKm}$.

- Penerapan aturan kelompok terutama penerapan sanksi pada tingkat kelompok tani.

- Pelibatan Balai Pemantapan Kawasan Hutan (BPKH) Wilayah XX dalam tata batas kawasan hutan.

- Koordinasi antar kabupaten terkait dengan fasilitasi dari pemerintah provinsi.

- Fasilitasi dari BPKH Wilayah XX dan LSM.

- Jika memungkinkan pemerintah daerah melalui pemerintah provinsi memfasilitasi permohonan bantuan pendanaan ke pemerintah pusat (Kementerian Kehutanan).

Sumber: Data primer diolah, 2014.

Program HKm baik pada pemerintah kabupaten maupun pemerintah provinsi masih belum menjadi program prioritas sehingga anggaran untuk $\mathrm{HKm}$ kurang memadai/terbatas. Hal ini menyebabkan kegiatan sosialisasi, pembinaan, dan koordinasi dalam implementasi $\mathrm{HKm}$ menjadi terhambat. Menurut Suhirman dkk. (2012), pemerintah daerah mempunyai peran sentral dalam kebijakan HKm, tidak hanya untuk menerbitkan izin dan pemanfaatan, tetapi juga mempunyai kewajiban untuk melakukan fasilitasi bagi pengembangan $\mathrm{HKm}$ di wilayahnya mulai perencanaan, inisiasi, pendampingan, pengusulan sampai pembiayaan.

Hal ini menunjukkan masih adanya persepsi dari pemerintah provinsi dan pemerintah kabupaten yang menganggap bahwa sebagai program dari 
pemerintah pusat, pendanaan HKm juga seharusnya berasal dari pemerintah pusat (Kementerian Kehutanan) baik secara langsung maupun melalui Balai Pengelolaan Daerah Aliran Sungai (BPDAS) sebagai Unit Pelaksana Teknis Kementerian Kehutanan. Menurut Suhirman dkk. (2012), kondisi ini diperparah dengan status bidang kehutanan sebagai urusan pilihan, keterbatasan anggaran dan personil lapangan.

\section{Kondisi yang Diharapkan}

Provinsi Lampung sudah mempunyai Forum HKm yang ditetapkan dengan SK Kepala Dinas Kehutanan Provinsi Lampung No SK.83/III.16/04/09. Fungsi dan tugas forum HKm ini di antaranya adalah menjaga agar kebijakan HKm tetap pada jalannya (on the track) dan membangun dukungan para pihak dalam penyelenggaraan $\mathrm{HKm}$. Terlepas dari masih adanya permasalahan dalam implementasi $\mathrm{HKm}$ di lapangan, $\mathrm{HKm}$ mempunyai beberapa manfaat baik bagi petani/masyarakat, pemerintah daerah (kabupaten/provinsi) maupun pemerintah pusat.

Bagi petani yang sangat tergantung dengan kawasan hutan, HKm memberikan keamanan dan kepastian dalam melakukan pengelolaan $\mathrm{HKm}$ sebagai sumber pendapatan. Bagi pemerintah daerah, HKm dianggap sebagai salah satu model pemberdayaan masyarakat yang memberikan peluang terhadap masyarakat untuk mendapatkan manfaat dengan tetap menjaga fungsi hutan. Sementara bagi bagi pemerintah pusat, HKm selain untuk meningkatkan kesejahteraan masyarakat juga untuk mempertahankan kawasan hutan terutama bagi kawasan yang sudah terlanjur digarap oleh masyarakat.

Berdasarkan hal tersebut dan wawancara dengan stakeholder terkait seperti petani, kelompok tani, pejabat Dinas Kehutanan Kabupaten/Provinsi,
BPDAS Way Sekampung Seputih, dan LSM WATALA diketahui beberapa kondisi yang diharapkan agar tujuan HKm dapat tercapai seperti ditunjukkan Tabel 3.

Pengembangan kelembagaan kelompok tani, pengelolaan lahan, dan pengembangan kewirausahaan merupakan tiga kunci penting yang harus mendapatkan dukungan dari berbagai pihak terkait sesuai dengan perannya masing-masing agar implementasi $\mathrm{HKm}$ dapat berjalan sesuai dengan tujuan $\mathrm{HKm}$ yakni untuk meningkatkan kesejahteraan masyarakat dengan tetap menjaga kelestarian hutan. Kondisi ini sejalan dengan Kaskoyo dkk. (2014) yang menyatakan bahwa untuk meningkatkan implementasi $\mathrm{HKm}$, pemberdayaan masyarakat baik secara individu maupun kelembagaan harus dibangun sehingga masyarakat mempunyai kesadaran dan kemampuan untuk mengelola hutan secara lestari. Pendampingan dari LSM, universitas, pemerintah, dan stakeholder lain juga diperlukan agar petani dapat mengimplementasikan HKm dengan baik.

\section{KESIMPULAN}

Hutan Kemasyarakatan (HKm) di Provinsi Lampung merupakan solusi terhadap permasalahan konflik pengelolaan hutan dengan tingkat ketergantungan masyarakat terhadap hutan yang tinggi telah mendorong kegiatan penggarapan lahan di kawasan hutan. HKm di Provinsi Lampung tersebar di 9 kabupaten dari 15 kabupaten/kota yang ada baik yang sudah mendapatkan IUPHKm, mendapatkan PAK, maupun sedang mengusulkan PAK. Permasalahan utama dalam implementasi $\mathrm{HKm}$ adalah dukungan anggaran dari pemerintah daerah kurang memadai akibat $\mathrm{HKm}$ belum menjadi program prioritas sehingga pembinaan dan pendampingan yang dilakukan kurang maksimal.

Tabel 3. Kondisi yang diharapkan dalam implementasi HKm di Lampung

\begin{tabular}{|c|c|c|c|c|c|}
\hline $\begin{array}{c}\text { Kondisi yang } \\
\text { diharapkan }\end{array}$ & Petani & $\begin{array}{l}\text { Pemerintah } \\
\text { kabupaten }\end{array}$ & Pemerintah provinsi & Pemerintah pusat & LSM \\
\hline $\begin{array}{l}\text { Kelembagaan } \\
\text { kelompok tani }\end{array}$ & $\begin{array}{l}\text { Perlu figur/tokoh yang } \\
\text { bisa menjadi panutan } \\
\text { dalam penerapan aturan } \\
\text { kelompok. }\end{array}$ & $\begin{array}{l}\text { Penguatan anggaran } \\
\text { untuk } \\
\text { mengintensifkan } \\
\text { pembinaan dan } \\
\text { pendampingan. }\end{array}$ & $\begin{array}{l}\text { Penguatan anggaran } \\
\text { untuk } \\
\text { mengintensifkan } \\
\text { pembinaan dan } \\
\text { pendampingan. }\end{array}$ & $\begin{array}{l}\text { Fasilitasi } \\
\text { pengembangan } \\
\text { usaha kelompok. }\end{array}$ & $\begin{array}{l}\text { Pendampingan } \\
\text { dan } \\
\text { pengembangan } \\
\text { kelembagaan } \\
\text { kelompok. }\end{array}$ \\
\hline Lahan & $\begin{array}{l}\text { - Pemahaman hak dan } \\
\text { kewajiban misalnya } \\
\text { penataan areal kerja } \\
\text { setelah mendapatkan } \\
\text { PAK. } \\
\text { - Peningkatan jumlah } \\
\text { tutupan lahan. }\end{array}$ & $\begin{array}{l}\text { - Fasilitasi proses } \\
\text { pemetaan lahan } \\
\text { garapan. } \\
\text { - Fasilitasi proses } \\
\text { pengurusan } \\
\text { IUPHKm. }\end{array}$ & $\begin{array}{l}\text { Fasilitasi } \\
\text { permasalahan HKm } \\
\text { lintas kabupaten. }\end{array}$ & $\begin{array}{l}\text { Fasilitasi tata batas } \\
\text { dan proses pemetaan } \\
\text { lahan garapan. }\end{array}$ & $\begin{array}{l}\text { Fasilitasi proses } \\
\text { pemetaan lahan } \\
\text { garapan. }\end{array}$ \\
\hline Kelola usaha & $\begin{array}{l}\text { Perlu orientasi kelola } \\
\text { usaha dan tidak terjebak } \\
\text { hanya dalam urusan } \\
\text { administrasi. }\end{array}$ & $\begin{array}{l}\text { Fasilitasi teknologi } \\
\text { pengolahan dan } \\
\text { pasca panen. }\end{array}$ & $\begin{array}{l}\text { Penguatan } \\
\text { kewirausahaan dan } \\
\text { fasilitasi jaringan } \\
\text { pemasaran. }\end{array}$ & $\begin{array}{l}\text { Penguatan } \\
\text { kewirausahaan dan } \\
\text { fasilitasi jaringan } \\
\text { pemasaran. }\end{array}$ & $\begin{array}{l}\text { Fasilitasi } \\
\text { teknologi } \\
\text { pengolahan dan } \\
\text { pasca panen. }\end{array}$ \\
\hline
\end{tabular}


Pengembangan kelembagaan kelompok tani, lahan, dan kewirausahaan merupakan tiga kunci penting dalam mencapai tujuan $\mathrm{HKm}$ yakni untuk meningkatkan kesejahteraan masyarakat dan menjaga kelestarian hutan.

\section{DAFTAR PUSTAKA}

Albrecht, A. dan Kandji, S., 2003. Carbon Sequestration in Tropical Agroforestry Systems Agriculture. Ecosystems and Environment. 99:15-27.

Anonim, 2007. Analisa Sosial Ekonomi Community Based Forest Management Kabupaten Lampung Barat, Provinsi Lampung. Dinas Kehutanan dan Pengelolaan Sumberdaya Alam Kabupaten Lampung Barat, UNDIP, WWF, ICRAF, dan WATALA, Liwa.

Anonim, 2012 . Hutan Kemasyarakatan di Provinsi Lampung. Dinas Kehutanan Provinsi Lampung, Bandarlampung.

Anonim, 2012 ${ }^{\mathrm{b}}$. Refleksi Percepatan Implementasi Hutan Kemasyarakatan (HKm) di Lampung Menuju Masyarakat Sejahtera dan Kelestarian Hutan. WATALA, Dinas Kehutanan Provinsi Lampung, dan Kemitraan, Bandar Lampung.

Anonim, 2014 ${ }^{\text {a }}$ Laporan Bulanan Data Sosial Ekonomi September 2014. Badan Pusat Statistik, Jakarta.

Anonim, 2014 ${ }^{\mathrm{b}}$. Data Perkembangan Pemanfaatan Kawasan Hutan sampai dengan Oktober 2012. Direktorat Jenderal Planologi Kehutanan, Kementerian Kehutanan, Jakarta.

Arifin, B., 2006. Transaction Cost Analysis of Upstream-Downstream Relations in Watershed Services: Lessons From Community-Based Forestry Management in Sumatra, Indonesia. Quarterly Journal of International Agriculture. 45:361-376.

Arifin, B., Swallow, B.M., Suyanto, S., dan Coe, R., 2009. Analysis A Conjoint Analysis of Farmer Preferences for Community Forestry Contracts in The Sumber Jaya Watershed, Indonesia. Ecological Economics. 68:20402050.

Awang, S.A., Suhardi, Safitri, M.A., dan Kustomo, 2000. Kelembagaan Kehutanan Masyarakat: Belajar dari Pengalaman. Pustaka Kehutanan Masyarakat, Yogyakarta.

Barr, C., Wollenberg, E., Limberg, G., Anau, N., Iwan, R., Sudana, I.M., dan Moeliono, M., 2001. Case Study 3, Case studies on decentralisation and forest in Indonesia. The Impacts of Decentralisation on Forest and Forest-Dependent Communities in Malinau District, East Kalimantan. Center for
International Forestry Research (CIFOR), Bogor, Indonesia.

Beer, J., Muschler, R., Kass, D., dan Somarriba, E., 1998. Shade Management in Coffee and Cacao Plantations. Agroforestry Systems. 38:139-164.

Dwiprabowo, H., Mulyaningrum, dan Suwarno, E., 2013. Organisasi Belajar dan Implementasi Kebijakan Hutan Kemasyarakatan (HKm). Jurnal Penelitian Sosial dan Ekonomi Kehutanan, 10(2):85-98.

Fay, C., Sirait, M., dan Kusworo, A., 2000. Getting The Boundaries Right: Indonesia's Urgent Need to Redefine its Forest Estate. International Centre for Research in Agroforestry, Bogor.

Kaskoyo, H., Mohammed, A.J., and Inou, M., 2014. Present State of Community Forestry (Hutan Kemasyarakatan/HKm) Program in a Protection Forest and Its Challenges: Case Study in Lampung Province, Indonesia. Journal of Forest Science. 30(1):15-29.

Maryudi, A., Devkota, R.R., Schusser, C., Yufanyi, C., Salla, M., Aurenhammer, $\mathrm{H}$, Rotchanaphatharawit, R, dan Krott, M., 2012. Back to Basics: Considerations in Evaluating The Outcomes of Community Forestry. Forest Policy and Economics. 14(1):1-5.

Obidzinski, K. dan Barr, C., 2003. Case Study 9, Case Studies on Decentralisation and Forests in Indonesia. The Effects Decentralisation on Forest and Forest Industries in Berau District, East Kalimantan. Center for International Forestry Research (CIFOR), Bogor, Indonesia.

Pahlawanti, R. dan Saroso, O., 2009. Hutan Kemasyarakatan: Melestarikan Hutan untuk Kesejahteraan Rakyat-Catatan 10 Tahun Program HKm di Provinsi Lampung. WATALA dan Partnership for Governance Reform in Indonesia (PGR Indonesia), Bandar Lampung.

Philpott, S.M., Arendt, W.J., Armbrecht, I., Bichier, P., Diestch, T.V., Gordon, C., Greenberg, R., Perfecto, I., Reynoso-Santos, R., Soto-Pinto, L., Tejeda-Cruz, C., Williams-Linera, G., Valenzuela, J., dan Zolotoff, J.M., 2008. Biodiversity Loss in Latin American Coffee Landscapes: Review of The Evidence on Ants, Birds, and Trees. Conservation Biology. 22(5):1093-1105.

Prayitno, H., Taufik, A., Fitriyani, R., Ramdan, D., Gunawan, dan Putra, R.A.S., 2013. Membongkar Harta Daerah: Analisis Kebijakan Anggaran Pengelolaan Hutan dan Lahan di 3 Provinsi dan 6 Kabupaten di 
Indonesia. Seknas FITRA, The Asia Foundation dan UKAID, Jakarta.

Safitri, M.A., 2006. Change without Reform? Community Forestry in Decentralizing Indonesia. The $11^{\text {th }}$ IASCP Conference. Bali, 19-23 Juni 2006.

Scarvada, A.J., Tatiana, B.C., Susan, M.G., dan Julie, M.H., dan Arthur, V.H., 2004. A Review of the Causal Mapping Practice andResearch Literature. Second World Conference on POM and 15th Annual POM Conference. Mexico, Cancun, 30 April - 3 Mei 2004.

Suhirman, Alamsyah, Z., Zaini, A., Sulaiman, dan Nikoyan, A., 2012. Studi Perencanaan dan Penganggaran Bagi Pengelolaan Hutan Berbasis Masyarakat di Indonesia: Studi Kasus Provinsi Jambi, Kalimantan Barat, Nusa Tenggara Barat, Sulawesi Tenggara. Laporan Utama Sebagai Hasil Studi Lapangan. Kemitraan (Bagi Pembaruan Tata Kepemerintahan di Indonesia).

Suyanto, S., Permana, R.P., Khususiyah, N., dan Joshi, L., 2005. Land Tenure, Agroforestry
Adoption, and Reduction of Fire Hazard in a Forest Zone: A Case Study From Lampung, Sumatra, Indonesia. Agroforestry System. 65:1-11.

Verbist, B. dan Pasya, G., 2004. Perspektif Sejarah Status Kawasan Hutan, Konflik dan Negosiasi di Sumberjaya, Lampung Barat, Provinsi Lampung. Jurnal Agrivita, 26(1):20-28.

Verbist, B., Ekadinata, A., dan Budidarsono, S., 2004. Penyebab Alih Guna Lahan dan Akibatnya terhadap Fungsi Daerah Aliran Sungai (DAS) pada Lansekap Agroforestri Berbasis Kopi di Sumatra. Jurnal Agrivita, 26(1):29-38.

Verbist, B, Ekadinata, A., dan Budidarsono, S., 2005. Factors Driving Land Use Change: Effects on Watershed Functions in a Coffee Agroforestry System in Lampung, Sumatra. Agricultural Systems. 85:254-270.

Widyastuti, S., 2013. Kajian Nilai Hutan Kemasyarakatan di Provinsi Lampung dan Kontribusinya pada Pembangunan Daerah. WATALA, Bandar Lampung. 